\title{
Dördüncü Sınıf Matematik Çalışma Kitabında Yer Alan Soruların TIMSS Sınavı Bağlamında İncelenmesi
}

DOI: 10.26466/opus.927449

\author{
Özlem Özçakır Sümen * \\ * Dr. Öğr. Üyesi, Ondokuz Mayıs Üniversitesi, Eğitim Fakültesi, Samsun/Türkiye \\ E-Posta: ozlem.ozcakir@omu.edu.tr \\ ORCID: $\quad$ 0000-0002-5140-4510
}

Öz

Ders kitapları, eğitim programlarının sinıflarda yürütülmesini sağlayan uygulama araçlarıdır. Araştırmalar, äğrencilerin ders ve çalışma kitaplarında karşllaştıları soruların uluslararası sinavlardaki matematik başarlların etkilediğini göstermektedir. Bu nedenle bu çalı̧̧mada dördüncü sını matematik dersi çalışma kitabında yer alan soruları TIMSS sınavı bağlamında incelenmesi amaçlanmıştır. Nitel araşıtrma yaklaşımı çerçevesinde doküman analizinin kullanıldığı araştırmada, 2020-2021 eğ̈itim-öğretim yllinda devlet okullarının dördüncü sinfflarında okutulan bir çallşma kitabı seçilmiş ve içerdiği sorular TIMSS sinav dikkate alnarak analiz edilmiş̧tir. Bu amaçla öncelikle matematik dersi öğretim programinda dördüncü smnfa ait matematik öğrenme ve alt öğrenme alanlarını içeren bir tablo oluşturulmuştur. Bu tabloya göre çalş̧ma kitabındaki sorular analiz edilerek yer aldıkları bilişsel basamaklar belirlenmiştir. Daha sonra frekans ve yüzde değerleri hesaplanmıştır. Analiz sonuçları, çalı̧̧ma kitabındaki "veri" öğrenme alannna ait sorularm TIMSS stnavina ait soru oranlarını oldukça altında kaldığın göstermiştir. Ayrıca sorular bilişsel basamaklarina göre incelendiğinde, "uygulama" düzeyindeki soru yüzdesinin TIMSS sinavina göre fazla oldŭ̆u ancak "akıl yürütme" düzeyinde TIMSS sinavinn altında kaldı̆̆ belirlenmiştir.

Anahtar Kelimeler: Dördüncü sınıf, matematik çalışma kitabı, TIMSS sınavı. 
Cilt Volume: 18

\title{
Examining the Questions of the Fourth-Grade Mathematics Workbook in the Context of TIMSS Exam
}

\begin{abstract}
Textbooks are application tools that enable educational programs to be carried out in classrooms. Studies show that the questions faced by students in their courses and workbooks affect their mathematics achievement in international exams. Therefore, in this study, it is aimed to examine the questions in the fourth-grade mathematics workbook in the context of the TIMSS exam. Document analysis method was used in the study. A fourth-grade workbook used in public schools in the 20202021 academic year was selected and the questions it contained were analyzed considering the TIMSS exam. For this purpose, first, a table containing the mathematics content domains belonging to the fourth grade in the mathematics curriculum was created. By analyzing the questions in the workbook, the cognitive levels of them were determined, and the frequency and percentage values were calculated. The results of the analysis showed that the ratio of the questions in the "data" domain in the workbook was well below the question rates of the TIMSS exam. In addition, when the questions were examined according to the cognitive levels, it was determined that the percentage of questions at the "applying" level was higher than the TIMSS exam but fell below the TIMSS exam at the "reasoning" level.
\end{abstract}

Keywords: Fourth-grade, mathematics workbook, TIMSS exam. 


\section{Giriş}

TIMSS (Uluslararası Matematik ve Fen Eğilimleri Araştırması) dört yılda bir yapılan ve dördüncü ve sekizinci sınıf öğrencilerinin matematik ve fen alanlarındaki başarılarını değerlendiren uluslararası bir sınavdır. İlk defa 1995 yılında gerçekleştirilen TIMSS sınavına Türkiye sekizinci sınıf düzeyinde 1999, dördüncü sınıf düzeyinde ise 2011 yılından beri katılmaktadır (Milli Eğitim Bakanlığı [MEB], 2020). 2019 yılında yedincisi yapılan TIMSS sınavına 64 ülke katılmış ve dördüncü sınıf matematik alanında Singapur 625, Hong Kong 602, Kore 600 puanla ilk üç sırayı alan ülkeler olmuştur. Türkiye ise 523 puanla 23. sırada yer almıştır ve öğrencilerin \%70'i orta düzey sinıflamasına girmiştir (Mullis, Martin, Foy, Kelly ve Fishbein, 2020; MEB, 2020).

Ders kitapları, matematik öğrenme-öğretme sürecinde önemli birer araçtır (Cai, 2008; Cai ve Ni, 2011; Fan, Zhu ve Miao, 2013; Stein, Remillard ve Smith, 2007). Ayrıca öğrencilerin matematik derslerinde kullandığı kitaplar başarılarını etkilemektedir (Reys ve Reys, 2006; Stein vd., 2007). Bu nedenle bu çalışmada dördüncü sınıf matematik çalışma kitabında yer alan soruların TIMSS sınavı bağlamında incelenmesi amaçlanmıştır. $\mathrm{Bu}$ konuda dördüncü sınıf düzeyinde yapılmış çalışmaların azlığı (Çilingir ve Artut, 2016; Toptaş, Elkatmış ve Karaca, 2012) alanda duyulan ihtiyacı göstermektedir. Bu yönüyle çalışma alana katkı sağlayacaktır. Ayrıca çalışma sonuçlarının önceki çalışmaların sonuçlarıyla karşılaştırılması ders kitaplarında gelinen noktayı gösterecektir.

\section{Teorik Çerçeve}

TIMSS sınavı Boston Lynch Eğitim Okulu'ndaki TIMSS \& PIRLS Uluslararası Eğitim Merkezi tarafından yönetilmektedir. TIMSS, uluslararası bir okuma değerlendirmesi olan PIRLS (Uluslararası Okuma Okuryazarlığı İlerleme Çalışması) ile birlikte matematik, fen ve okuma olmak üzere üç temel konudaki başarıyı ölçmektedir. TIMSS; öğrencilerden, ebeveynlerden, öğretmenlerden ve okul müdürlerinden öğrencilerin ev-okul yaşantıları ve matematik-fen öğrenimleriyle ilgili anketler doldurmalarını istemektedir. Böylece öğrenci başarısını farklı 
değişkenler açısından inceleyerek sonuçlara geniş bir bakış açısı sunmaktadır (Mullis, 2017). TIMSS, öğrenci başarısını ve bu başarıyı etkileyen faktörleri değerlendirmede eğitim programlarını kullanmaktadır. TIMSS Eğitim Programı Modeli'nin üç yönü vardır: planlanan program, uygulanan program ve ulaşılan program (bkz. Şekil 1). Planlanan program, ülkelerin müfredat politikaları ve yayınlarıla öğrencilerden öğrenmeleri beklenen matematik ve feni, bununla birlikte öğrencilerin öğrenmesini kolaylaştırmak için eğitim sisteminin nasıl organize edilmesi gerektiğini temsil eder. Uygulanan program, sinıflarda gerçekte ne öğretildiğini, onu öğretenlerin özelliklerini ve programın nasıl öğretildiğini gösterir. Son olarak, ulaşılan program ise öğrencilerin ne öğrendiklerini ve bu konularla ilgili ne düşündüklerini içerir (Mullis, 2017).

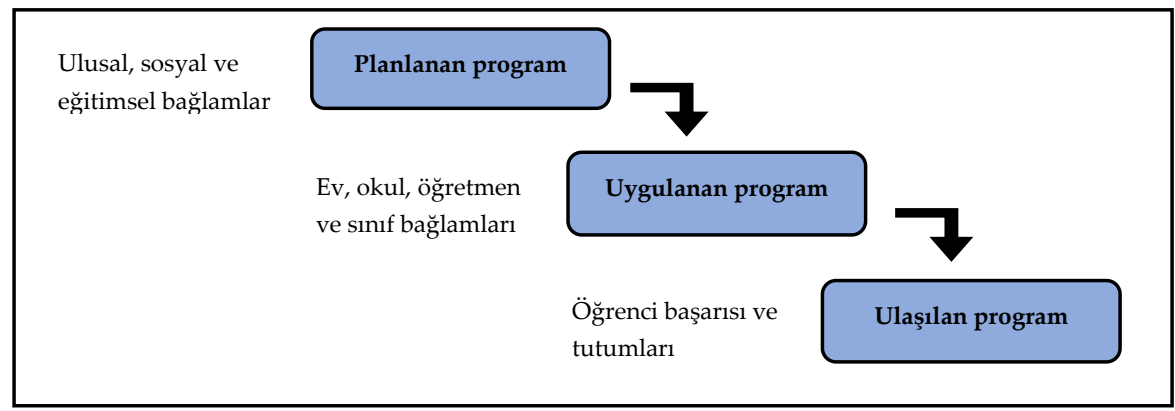

Şekil 1. TIMSS Ĕ̆itim Programı Modeli (Mullis, 2017'den uyarlanmıştır)

TIMSS'in Eğitim Programı Modeli'nde öğrenci çalışma kitapları, planlanan ve uygulanan program arasında aracı rolü üstlenen anahtar bir rol oynamaktadır (Valverde, Bianchi, Wolfe, Schmidt ve Houang, 2020). Eğitim programları amaçlar doğrultusunda şekillendirilir ancak programlarda içeriği öğrencilere kavratmak için gereken eğitimsel aktiviteler ve işlemler yer almaz. Çalışma kitapları, öğretmenlerin ve öğrencilerin planlanan programda sunulan fikirler ile sınıfın çok farklı dünyası arasında bağlantı kurmalarını sağlar. Ayrıca öğretmen ve öğrencilere somut eylemler sunarak planlanan ve uygulanan program arasında aracı rol oynar, okul konularının öğrenilmesi için fırsatlar sağlar ve eğitim üzerinde karakteristik etkileri vardır (Valverde vd., 
2020). Programların öğrencilerin konuları öğrenmesine olanak sağladığ1 için öğrenci başarısı üzerinde büyük bir etkisi vardır; ders kitapları ise bu olanakları öğrencilere sağlar(Schmidt vd., 2001). Nitekim bu durum TIMSS sınavı sonuçlarıyla da teyit edilmiştir. Singapur'un TIMSS sınavında yüksek başarı göstermesi ve buradaki çocukların matematik performansı, matematiğin ders kitaplarında sunulma biçimine bağlanmıştır (Beckmann, 2004).

Alan yazında ortaokul matematik kitaplarının TIMSS (Güner, 2020) ve PISA matematik yeterlik düzeyleri (Aydoğdu-İskenderoğlu ve Baki, 2011; Şaban, 2019) açısından incelendiği çalışmalar yürütülmüştür. Matematik ders kitaplarındaki soruları yenilenmiş Bloom taksonomisine göre inceleyen çalışmalar da yapılmıştır (Üredi ve Hakan, 2020). Ayrıca ders kitapları dışında TEOG sınavı sorularını ve Bursluluk Sınavı sorularını TIMSS sınavı ile bilişsel açıdan karşılaştıran çalışmalar mevcuttur (Çalışkan, Kahya ve Durmuş, 2018; Delil, 2019). Ancak ilkokul dördüncü sınıf matematik kitaplarının TIMSS'e göre analiz edildiği çalışma sayısı sınırlıdır (Çilingir ve Artut, 2016; Toptaş vd., 2012). Bu nedenle, bu çalışmada dördüncü sınıf matematik dersi çalışma kitabı TIMSS sınavı açısından değerlendirilmiştir. Çalışma sonuçlarının önceki çalışmaların sonuçlarıyla karşılaştırılması ders kitaplarında gelinen noktayı göstermesi açısından alana katkı sağlayacaktır. Bu doğrultuda çalışmanın alt problemleri şunlardır;

Dördüncü sınıf matematik dersi çalışma kitabında yer alan soruların;

1. Bilişsel basamakları öğrenme alanlarına göre nasıl bir dağılım göstermektedir?

2. Öğrenme alanları TIMSS sınavı ile karşılaştırıldığında nasıl bir dağılım göstermektedir?

3. Bilişsel basamakları TIMSS sınavı ile karşılaştırıldığında nasıl bir dağılım göstermektedir?

\section{Yöntem}

$\mathrm{Bu}$ çalışma nitel araştırma yaklaşımı çerçevesinde doküman analizi kullanılarak gerçekleştirilmiştir. Nitel araştırma açık ve esnek bir tasarım kullanır ve konuya bütüncül ve kapsamlı bir yaklaşım sunar; böylece araştırma sonucunda daha zengin ve betimleyici bulgular elde edilir 
(Corbin ve Strauss, 2008). Doküman analizi ise araştırma konusu ile ilgili basılı veya elektronik belgelerin gözden geçirilmesi ve değerlendirilmesi için gerçekleştirilen sistematik işlemleri içerir (Bowen, 2009; Yıldırım ve Şimşek, 2006). Doküman analizi, anlama, anlam çıkarma ve empirik bilgi geliştirme amaçlarıla verinin incelenmesine ve yorumlanmasina dayanan (Corbin ve Strauss, 2008), ayrıca gözden geçirme (yüzeysel inceleme), okuma (kapsamlı inceleme) ve yorumlama aşamalarından oluşan bir desendir/süreçtir (Bowen, 2009). Bu bağlamda çalışma kapsamında ilkokul dördüncü sınıf matematik dersi çalışma kitabı TIMSS sınavı referans alınarak analiz edilmiştir.

\section{Veri Toplama Araçları}

Çalışmada Milli Eğitim Bakanlığı tarafından 2020-2021 eğitim yılı için önerilen ve devlet okullarında okutulan İlkokul 4. Sınıf Matematik Dersi Çalışma Kitabı (Savaş, Olkay, Turan Ekmekçi ve Savaş, 2020) incelenmiş ve içerdiği sorular analiz edilerek TIMSS sınavının kapsadığı sorularla karşılaştırılmıştır.

\section{Veri Analizi}

Veri analizi aşamasında öncelikle Matematik Dersi Öğretim Programı (Milli Eğitim Bakanlığı [MEB], 2018) incelenerek 4. sınıfa ait öğrenme alanları ve alt öğrenme alanlarını içeren bir tablo hazırlanmıştır. Tabloda her bir öğrenme alanına ait alt öğrenme alanlarından benzer olanlar aynı başlık altında birleştirilmiştir. Örneğin, "Doğal Sayılar” alt öğrenme alanı tabloda aynen yer alırken, doğal sayılarda toplama, çıkarma, çarpma ve bölme işlemlerine yönelik sorular "Doğal Sayılarda İşlemler" başlığı altında incelenerek sunulmuştur. Öğrenme alanları ve alt öğrenme alanları oluşturulduktan sonra tablolara bilişsel alan basamakları eklenmiştir. Çalışma kitabında yer alan problemlerin, soruların ve alıştırmaların tamamı incelenerek yer aldıkları bilişsel basamaklar belirlenmiştir. Soruların yer aldığı bilişsel basamakların belirlenmesinde TIMSS sinavinda bilme, uygulama ve akıl yürütme basamaklarının kapsadığı eylemlere yönelik verilen çerçeve 
kullanılmıştır (Mullis vd., 2020; MEB, 2020). Bu bilişsel basamakların kapsadığı eylemler Tablo 1'de sunulmuştur.

Tablo 1. TIMSS 2019 sınavına göre sorularn bilişsel basamaklan

\begin{tabular}{ll}
\hline Bilişsel basamaklar & Eylemler \\
\hline Bilme & Hatırlama \\
& Tanıma/ayırt etme \\
& Sinıflandırma/sıralama \\
& İşlem yapma \\
& Bilgiyi anlama/okuma \\
& Ölçme \\
\hline Uygulama & Belirleme/karar verme \\
& Sunma/modelleme \\
& Uygulama \\
\hline Akıl yürütme & Analiz etme \\
& Sentez yapma \\
& Değerlendirme \\
& Sonuç çıarma \\
& Genelleme \\
& Doğrulama \\
\hline
\end{tabular}

Kaynak: MEB (2020)'den uyarlanmıştır.

Çalışma kitabında yer alan sorular tek tek analiz edilerek tabloda uygun öğrenme alanlarına kodlanarak yazılmıştır. Daha sonra yapılan kodlamalara ait frekans ve yüzde değerleri hesaplanmış ve TIMSS 2019 sınavına ait soru oranları ile karşılaştırılmıştır. TIMSS 2019 sınavı dördüncü sınıf düzeyindeki matematik sorularının \%50'si "Sayılar", \%30'u "Ölçme ve Geometri", \%20'si "Veri" öğrenme alanında sorulmuştur. Ayrıca bu sorular \%40 oranında "bilme", \%40 oranında "uygulama" ve \%20 oranında "akıl yürütme" bilişsel basamaklarını içermektedir (Mullis vd., 2017). Kodlama işlemi bittikten sonra tüm yapılan analizler matematik eğitimi alanında çalışan bir uzmana sunulmuş ve tüm soruları bağımsız biçimde incelemesi ve her bir sorunun yer aldığ bilişsel basamağ belirlemesi istenmiştir. Analiz işlemi bittikten sonra, araştırmacı ve uzman tarafından yapılan analizler karşılaştırılmış, farklılıklar belirlenmiş ve sebepleri tartışılmıştır. Tüm bu işlemler neticesinde ortak bir görüşe varılarak veri analizine son şekli verilmiştir. 


\section{Bulgular}

Bu bölümde öncelikle soruların bilişsel basamakları öğrenme alanlarına göre sunulmaktadır. Tablo 2, soruların "Sayılar ve İşlemler" öğrenme alanına göre bilişsel basamaklarının dağılımını göstermektedir.

Tablo 2. Soruların bilişsel basamaklarının "Sayılar ve İşlemler" öğrenme alanına göre dă̆ılımı

\begin{tabular}{lllll}
\hline $\begin{array}{l}\text { Öğrenme } \\
\text { alanları }\end{array}$ & $\begin{array}{l}\text { Alt öğrenme } \\
\text { alanları }\end{array}$ & Bilişsel basamaklar & Frekans & Yüzde \\
\hline Sayılar ve & Doğal Sayılar & Bilme & 27 & 16,07 \\
İşlemler & & Uygulama & 0 & 0 \\
& & Akıl yürütme & 0 & 0 \\
\cline { 2 - 5 } & Doğal Sayılarda & Bilme & 23 & 13,69 \\
& İşlemler & Uygulama & 56 & 33,33 \\
& & Akıl yürütme & 19 & 11,31 \\
\cline { 2 - 5 } & Kesirler ve & Bilme & 9 & 5,36 \\
& Kesirlerde İşlemler & Uygulama & 34 & 20,24 \\
& & Akıl yürütme & 0 & 0 \\
\cline { 2 - 5 } & & & 168 & 100 \\
\hline \multirow{2}{*}{ Toplam } & & &
\end{tabular}

Tablo 2'de görüldüğü üzere, matematik dersi çalışma kitabında "Doğal Sayılar" alt öğrenme alanında yer alan tüm soruların ( $\mathrm{f}=27)$ bilme basamağında yer almaktadır. "Doğal Sayılarda İşlemler" konusuna ait sorular ise ağırlıklı olarak uygulama basamağında ( $\mathrm{f}=56$ ) yer almakla birlikte, bilme $(\mathrm{f}=23)$ ve akıl yürütme $(\mathrm{f}=19)$ alanlarında da sorular sorulduğu görülmektedir. "Kesirler ve Kesirlerde İşlemler" konusunda ise soruların daha çoğunlukla uygulama ( $\mathrm{f}=34)$ düzeyinde yer aldığı, bilme basamağında ( $\mathrm{f}=9$ ) daha az sorunun yer aldığı görülmektedir.

Tablo 3'de görüldüğü üzere, "Geometrik Cisimler ve Şekiller" alt öğrenme alanına ait sorular bilme ( $\mathrm{f}=10)$ ve uygulama $(\mathrm{f}=2)$; “Uzamsal İlişkiler" alt öğrenme alanına sorular uygulama (f=3); "Geometrik Örüntüler" soruları uygulama ( $\mathrm{f}=2$ ) ve akıl yürütme $(\mathrm{f}=4)$; "Geometride Temel Kavramlar" soruları bilme $(\mathrm{f}=6)$ ve uygulama $(\mathrm{f}=5)$ basamaklarında yer almaktadır.

Tablo 3. Soruların bilişsel basamaklarının "Geometrik Şekiller ve Ölçme" öğrenme alanına göre dă̆ılımı 


\begin{tabular}{lllll}
\hline $\begin{array}{l}\text { Öğrenme } \\
\text { alanları }\end{array}$ & $\begin{array}{l}\text { Alt öğrenme } \\
\text { alanları }\end{array}$ & Bilişsel basamaklar & Frekans & Yüzde \\
\hline Geometrik & Geometrik Cisimler & Bilme & 10 & 31,25 \\
Şekiller ve & ve Şekiller & Uygulama & 2 & 6,25 \\
Ölçme & Akıl yürütme & 0 & 0 \\
\cline { 2 - 5 } & Uzamsal İlişkiler & Bilme & 0 & 0 \\
& & Uygulama & 3 & 9,38 \\
& & Akıl yürütme & 0 & 0 \\
\cline { 2 - 5 } & Geometrik & Bilme & 0 & 0 \\
& Örüntüler & Uygulama & 2 & 6,25 \\
& & Akıl yürütme & 4 & 12,5 \\
\cline { 2 - 5 } & Geometride Temel & Bilme & 6 & 18,75 \\
& Kavramlar & Uygulama & 5 & 15,63 \\
\cline { 3 - 5 } & & Akll yürütme & 0 & 0 \\
\hline \multirow{2}{*}{ Toplam } & & & 32 & 100 \\
\hline
\end{tabular}

Tablo 4. Soruların bilişsel basamaklarının "Ölçme" öğrenme alanına göre dağılımı

\begin{tabular}{lllll}
\hline $\begin{array}{l}\text { Öğrenme } \\
\text { alanları }\end{array}$ & $\begin{array}{l}\text { Alt öğrenme } \\
\text { alanları }\end{array}$ & Bilişsel basamaklar & Frekans & Yüzde \\
\hline Ölçme & Uzunluk-Çevre- & Bilme & 13 & 12,5 \\
& Alan Ölçme & Uygulama & 21 & 20,2 \\
& Akıl yürütme & 7 & 6,73 \\
\cline { 2 - 5 } & Zaman Ölçme & Bilme & 4 & 3,85 \\
& Uygulama & 10 & 9,62 \\
& Akıl yürütme & 1 & 0,96 \\
\cline { 2 - 5 } & Tartma & Bilme & 9 & 8,65 \\
& Uygulama & 12 & 11,5 \\
& & Akıl yürütme & 3 & 2,88 \\
\cline { 2 - 5 } & Sivı Ölçme & Bilme & 6 & 5,77 \\
& & Uygulama & 14 & 13,5 \\
& & Akıl yürütme & 4 & 3,85 \\
\hline & & & 104 & 100 \\
\hline
\end{tabular}

Soruların "Ölçme" alanına göre bilişsel açıdan dağılımı Tablo 4'te görülmektedir ve soruların dağılımı şu şekildedir: “Uzunluk-Çevre-Alan Ölçme" alt öğrenme alanlarına ait bilme (f=13), uygulama ( $\mathrm{f}=21)$, akıl yürütme (f=7); "Zaman Ölçme" alanına ait bilme (f=4), uygulama (f=10), akıl yürütme ( $\mathrm{f}=1)$; “Tartma" öğrenme alanına ait bilme ( $\mathrm{f}=9)$, uygulama $(\mathrm{f}=12)$, akıl yürütme ( $\mathrm{f}=3)$; "Sıvı Ölçme" alanına ait bilme $(\mathrm{f}=6)$, uygulama $(\mathrm{f}=14)$, akıl yürütme $(\mathrm{f}=4)$ basamaklarında sorular yer almaktadır. Tablo 5. Soruların "Veri İşleme" öğrenme alanına göre bilişsel açıdan dağılımı

\begin{tabular}{lllll}
\hline Öğrenme & Alt öğrenme & Bilişsel basamaklar & Frekans & Yüzde \\
\hline
\end{tabular}




\begin{tabular}{lllll}
\hline alanları & alanları & & & \\
\hline Veri İşleme & Veri Toplama ve & Bilme & 1 & 10 \\
& Değerlendirme & Uygulama & 2 & 20 \\
& & Akıl yürütme & 7 & 70 \\
\cline { 2 - 5 } & & & 10 & 100 \\
\hline
\end{tabular}

Tablo 5, çalışma kitabında "Veri İşleme" öğrenme alanında yer alan soruların bilişsel basamaklara göre dağılımını göstermektedir. Soruların çoğunluğu akıl yürütme basamağında ( $\mathrm{f}=7)$ yer almakla birlikte, bilme $(\mathrm{f}=1)$ ve uygulama $(\mathrm{f}=2)$ basamaklarına ait sorular da sorulmuştur.

Tablo 6. Soruların öğrenme alanlarına göre dağılımlarıın TIMSS sınavı ile karşılaştırılması

\begin{tabular}{llll}
\hline Öğrenme Alanı & $\begin{array}{l}\text { Toplam soru sayısı } \\
\text { (f) }\end{array}$ & $\begin{array}{l}\text { Tüm soru sayısına } \\
\text { yüzdesi }\end{array}$ & $\begin{array}{l}\text { TIMSS 2019 soru } \\
\text { yüzdesi }\end{array}$ \\
\hline Sayılar & 168 & $\% 53,5$ & $\% 50$ \\
Ölçme ve Geometri & $32+104=136$ & $\% 43,32$ & $\% 30$ \\
Veri & 10 & $\% 3,18$ & $\% 20$ \\
\hline Toplam & 314 & $\% 100$ & $\% 100$ \\
\hline
\end{tabular}

Tablo 6'da çalışma kitabında yer alan tüm soruların öğrenme alanlarına göre dağılımının TIMSS 2019'daki soru yüzdeleri ile karşılaştırılmasına yönelik veriler yer almaktadır. Çalışma kitabında yer alan soruların \%53,5'i "Sayılar" öğrenme alanındadır. Benzer biçimde TIMSS 2019 sinavında da soruların \%50'si "Sayılar" öğrenme alanındadır. Ancak "Ölçme ve Geometri" ve "Veri" öğrenme alanlarında soruların dağılımı farklılaşmaktadır. Çalışma kitabında yer alan soruların \%43,32'ü "Ölçme ve Geometri" öğrenme alanındayken, yalnızca \%3,18'i "Veri" öğrenme alanında yer almaktadır. TIMSS 2019 sinavında ise "Veri" öğrenme alanında sorulan soru yüzdesi \%20 ile daha büyük bir orana sahiptir.

Tablo 7'de, çalışma kitabındaki tüm soruların bilişsel basamaklara göre dağılımları görülmektedir. TIMSS 2019'da yer alan soru yüzdeleri ile karşılaştırıldığında, çalışma kitabındaki soruların \%51,27'si uygulama düzeyinde yer almaktadır. Bu bulgu, TIMSS sinavinda sorulan uygulama düzeyindeki soru oranından (\%40) daha büyüktür. Ancak tüm soruların \%34,39'u bilme basamağındadır ve TIMSS 2019'daki orandan (\%40) daha düşüktür. Benzer biçimde akıl yürütme 
basamağında tüm soruların \%14,34'ü yer almaktadır ve TIMSS 2019 sınavında \%20 oranında akıl yürütme sorusu sorulmuştur.

Tablo 7. Soruların bilişsel basamaklara göre dă̆ılımlarının TIMSS sınavı ile karşılaştırılması

\begin{tabular}{llll}
\hline Bilişsel Alan & $\begin{array}{l}\text { Toplam soru sayıs1 } \\
\text { (f) }\end{array}$ & $\begin{array}{l}\text { Tüm soru sayısına } \\
\text { yüzdesi }\end{array}$ & $\begin{array}{l}\text { TIMSS 2019 soru } \\
\text { yüzdesi }\end{array}$ \\
\hline Bilme & 108 & $\% 34,39$ & $\% 40$ \\
Uygulama & 161 & $\% 51,27$ & $\% 40$ \\
Akıl yürütme & 45 & $\% 14,34$ & $\% 20$ \\
\hline Toplam & 314 & $\% 100$ & $\% 100$ \\
\hline
\end{tabular}

\section{Tartışma ve Sonuç}

Matematik ders kitapları bir ülkenin matematik müfredatı ve matematik eğitimi tarihinin gelişimini gösterir ve zaman içinde matematik eğitimindeki değişiklikleri fark etmemize yardımcı olur (Baker, Knipe, Cummings, Blair ve Gamson, 2010). Bu nedenle matematik kitaplarının incelenmesi bir ülkede uygulanan matematik eğitiminin niteliğinin ortaya konulması açısından önemli veriler sağlayabilir. Bu araştırmada ilkokul dördüncü sınıf matematik dersi çalışma kitabının konu anlatımı ve bölüm sonu değerlendirmeleri dahil olmak üzere kitabın tamamında yer alan sorular TIMSS 2019 sinavı bağlamında incelenmiştir. Araştırma sonucunda, çalışma kitabında yer alan soruların "Sayılar ve İşlemler" öğrenme alanında tüm bilişsel basamakları içerirken, "Doğal Sayılar" konusunda sadece "bilme" basamağı ile sınırlı kaldığı görülmüştür. Ancak bu sorular da öğrencileri yorum yapmaya ve düşündürmeye yönelik ek sorularla desteklenmiştir. Bu, olumlu bir durumdur ancak doğal sayılar konusunda üst düzey bilişsel basamaklara yönelik sorulara da yer verilmesi gerekmektedir. Çünkü doğal sayılar tüm matematiğin temelini oluşturan bir konudur. Öğrencilere ezberden uzak, yaratıcı düşünmeye sevk eden, hayata eleştirel bakmayı sağlayan, günlük hayattan problem durumları içeren üst düzey sorular sorulması önemlidir (Ayvacı ve Türkdoğan, 2010).

Diğer öğrenme alanlarından "Uzamsal İlişkiler" konusuna yönelik soruların sayıca az olduğu tespit edilmiştir. Elbette ki kitapta yer alan soru sayıları konuların matematik programındaki kazanımları (MEB, 
2018) ile orantılıdır. Bu durum uzamsal ilişkiler konusunun dördüncü sınıfta sınırlı biçimde öğretilmesinden kaynaklanmaktadır. Ancak soru sayısının artırılması öğrencilerin konuyu daha iyi kavramalarını sağlayabilir. "Ölçme" öğrenme alanında ise tüm bilişsel basamaklara yönelik soruların yer aldığı görülmüştür.

Çalışma kitabında yer alan soruların öğrenme alanlarına göre dağılımı TIMSS sınavı ile karşılaştırıldığında, "Sayılar" öğrenme alanına ait soru yüzdesinin (\%53,5) TIMSS 2019'daki "Sayılar" soru yüzdesi (\%50) ile benzeştiği ortaya çıkmıştır. "Ölçme ve Geometri" soru alanında $(\% 43,3)$ TIMSS'e göre $(\% 30)$ daha fazla soru yer alırken, "Veri" öğrenme alanına ait soru yüzdesinin $(\% 3,18)$ TIMSS sınavına göre $(\% 20)$ oldukça az kaldığ 1 tespit edilmiştir. Bu alt öğrenme alanına ait soru sayısının azlığ 1 hem öğrencilerin bu alanda eksik kalmasına hem de TIMSS sınavında yeterince başarı gösterememelerine neden olabilir. Toptaş vd. (2012) inceledikleri ilköğretim 4. sınıf matematik çalışma kitabındaki soruların \%50,64 oranında "Sayılar", \%25,32 oranında "Geometrik Şekiller ve Ölçme", \%24,02 oranında ise "Verilerin Gösterimi" alanında yer aldığını tespit etmiştir. Araştırmacıların "Sayılar" öğrenme alanına ilişkin ulaştıkları sonuçların bu çalışmanın sonuçları ile oldukça benzer olduğu görülmektedir. Çalışma kitaplarının "Sayılar" konusundaki soru oranları TIMSS ile benzeşmektedir. Ancak araştırmacılar "Ölçme ve Geometri" öğrenme alanına ait soru oranını TIMSS'ten düşük, "Veri" konusunun ise TIMSS'ten büyük oranda soru içerdiğini rapor etmiştir. $\mathrm{Bu}$ çalışmada ise bu iki öğrenme alanına ait sonuçlar tam tersini göstermektedir. Bu durum zaman içinde matematik ders kitaplarındaki "Ölçme ve Geometri" alanındaki soru sayısının artırıldığını ve "Veri" alanına ait soruların azaltıldığını göstermektedir. Ancak çalışma kitabındaki soruların öğrenme alanlarına göre yüzdelik dağılımlarının TIMSS ile farklılık göstermesi doğal olarak öğrencilerin bu sınavdaki başarılarını etkileyecektir. Soruların öğrenme alanlarına göre düzenlenmesi ve "Veri" öğrenme alanına yönelik daha fazla soru sorulması gerekmektedir.

Çalışma kitabında yer alan soruların bilişsel basamaklarına göre dağılımları soruların büyük oranda uygulama düzeyinde yer aldığını göstermiştir. Bu oran TIMSS sınavındakinden daha büyük bir orandır. $\mathrm{Bu}$ durum olumlu olarak görülebilir. Çünkü uygulama düzeyi bilme 
basamağından daha üst düzeydedir. Ancak TIMSS sınavında yer alan soru yüzdeleri ile karşılaştırıldığında, çalışma kitabındaki soruların akıl yürütme basamağındaki soruların oranı TIMSS sınavındaki soru yüzdesinin oldukça altındadır. Bu da tam tersi olumsuz bir durumdur, bilişsel açıdan daha üst düzeydeki sorulara kitapta daha az yer verildiğini göstermiştir. Çalışmanın sonuçlarının bu alanda ilkokul düzeyinde yapılan çalışmalarla farklılıklar gösterdiği görülmektedir. Örneğin, Çilingir ve Artut (2016) 4. sınıf matematik ders kitabı geometrik şekiller konusundaki soruları TIMSS 2011 ile karşılaştırmış ve ders kitaplarındaki soruların genellikle bilgi basamağında yer aldığını, TIMSS sorularının ise daha üst bilişsel basamakları içerdiğini ortaya koymuştur. Toptaş vd. (2012) ise 4. sınıf matematik çalışma kitabında yer alan soruların \%41,55 oranında "bilme" (TIMSS bilme \%40), \%32,80 "uygulama" (TIMSS uygulama \%40), \%25,65 “akıl yürütme" (TIMSS akıl yürütme \%20) basamağında yer aldığını tespit etmiştir. Üredi ve Hakan (2020) ilkokul matematik ders kitaplarındaki soruları yenilenmiş Bloom taksonomisine göre incelediklerinde, 1 . ve 2. sınıf ders kitaplarındaki soruların tamamının alt düzey bilişsel becerileri; 3. ve 4 . sınıf ders kitaplarındaki soruların ise büyük bölümünün alt düzey bilişsel becerileri ölçtüğünü belirlemiştir. Ancak çalışmanın sonucunda 20202021 yılına ait bu çalışma kitabında bu oranların farklılaştığı tespit edilmiştir. Sonuçlar soruların çoğunlukla "uygulama" düzeyinde yer aldığını ortaya koymuştur. Bu sonuç, ders kitaplarında gelinen nokta açısından olumlu bir durumdur.

Çalışma sonuçları ortaokul ders kitaplarıyla yapılan çalışma sonuçları ile karşılaştırıldığında paralel sonuçlara ulaşıldığını göstermektedir. Benzer biçimde Delil (2006) de 6.- 8. sınıf matematik kitaplarının içerdiği soruları TIMSS 2003'te tanımlanan dört bilişsel düzeye (bilgi, kavramları kullanma, rutin problem çözümü, akıl yürütme) göre sinıflandırdığında, geometri sorularının $\% 9^{\prime}$ unun akıl yürütme düzeyinde olduğunu saptamıştır. Güner (2020), 2004 ve 2008 yıllarında basılan 6.- 8. sınıf matematik ders kitaplarının geometri, veri ve olasılık sorularını TIMSS bilişsel düzeylerine göre sınıflandırmış ve kitaplardaki geometri problemlerinin \%10'unun akıl yürütme düzeyinde olduğunu tespit etmiştir. Çalışkan vd. (2018) ise TEOG matematik soruları ile TIMSS 2015 sekizinci sınıf sorularını karşılaştırmış ve soruların yalnızca \%12'sinin 
"akıl yürütme" basamağında sorulduğunu tespit etmiştir. Ortaokul matematik dersi çalışma kitaplarındaki soruların PISA matematik yeterlik düzeylerine göre incelendiği çalışmalarda ise kitaplardaki soruların büyük bölümünün PISA yeterlik ölçeğine göre 1 . ve 2 . düzey sorulardan oluştuğu görülmüş; ayrıca kitaplarda PISA'nın üst düzey olarak tanımladığ 5 . ve 6 . seviyeden hiçbir örneğe rastlanmadığ 1 rapor edilmiştir (Aydoğdu-İskenderoğlu ve Baki, 2011; Şaban, 2019). Araştırma sonuçlarının çalışma kitabının "akıl yürütme" basamağında daha az oranda soru içermesi açısından tüm bu çalışmaların sonuçlarıyla paralel olduğu görülmektedir. Ancak her ne kadar çalışma kitabındaki sorular bilişsel açıdan "akıl yürütme" basamağında az oranda soru içerse de soruların büyük çoğunluğu "uygulama" düzeyindedir. Bu nedenle kitaptaki "akıl yürütme" sorularının artırılması gerekmekle birlikte sonuçlar kitabın yetersiz olduğunu göstermemektedir.

\section{Öneriler}

TIMSS sınavı sonucunda öğrencilerin matematik alanında gösterdikleri başarı düzeyleri; öğrencilere verilen eğitimin, eğitim programlarının, sınıf içi uygulamaların, derslerde kullanılan yöntem ve tekniklerin, okutulan kitapların, ölçme ve değerlendirme tekniklerinin yani eğitimi etkileyen tüm değişkenlerin ortak sonucudur. $\mathrm{Bu}$ nedenle ders kitaplarının da bu başarı üzerinde önemli bir etkisi vardır. Matematik ders ve çalışma kitaplarının TIMSS sınavına paralel şekilde düzenlenmesi öğrencilerin bu sınavdaki başarıları açısından önemlidir. Bu sebeple, dördüncü sınıf çalışma kitabında "akıl yürütme" bilişsel basamağına yönelik daha fazla soru yer almalıdır. Öğrenme alanları açısından ise "veri" alanına yönelik daha fazla soruya yer verilmelidir. 


\section{EXTENDED ABSTRACT}

\section{Examining the Questions of the Fourth-Grade Mathematics Workbook in the Context of TIMSS Exam

\author{
* \\ Özlem Özçakır Sümen \\ Ondokuz Mayıs University
}

The TIMSS (Trends in International Mathematics and Science Study) is an international exam held every four years that evaluates fourth and eighth-grade students' achievement in mathematics and science. Turkey has been taking the TIMSS exam since 1999 at the eighth-grade level and since 2011 at the fourth-grade level (MoNE, 2020). Sixty-four countries participated in the TIMSS exam, which was held for the seventh time in 2019, and Turkey ranked 23rd in fourth-grade mathematics with 523 points (Mullis et al., 2020; MoNE, 2020). Textbooks are essential tools in the mathematics teaching and learning process (Cai, 2008; Cai \& Ni, 2011; Fan et al., 2013; Stein et al., 2007). Besides, the books that students use in mathematics lessons affect their success (Reys \& Reys, 2006; Stein et al., 2007). Therefore, this study aimed to examine the questions in the fourth-grade mathematics workbook in the context of the TIMSS exam.

This study was carried out using document analysis. In the study, the Primary School Fourth-Grade Mathematics Workbook (Savaş et al., 2020) recommended by the Ministry of National Education for the 2020-2021 academic year was examined, and the questions were analyzed and compared with the questions covered by the TIMSS exam. In the data analysis, a table containing the mathematics topics of the fourth grade was prepared according to the Mathematics Curriculum (MoNE, 2018), and content domains were created. The framework covered by the knowing, applying, and reasoning steps in the TIMSS exam were used to determine the cognitive levels of the questions (Mullis et al., 2020; MoNE, 2020). The questions in the workbook were analyzed and coded into the appropriate content domains in the table. Then, the frequency and percentage values were calculated and compared with the question rates of the TIMSS 2019 exam. 
As a result of the research, it was found that $53.5 \%$ of the questions in the workbook were in the content domain of "Numbers." Similarly, 50\% of the questions in the TIMSS 2019 exam are in the "Numbers" domain. However, the distribution of questions differs in the "Measurement and Geometry" and "Data" domains. While $43.32 \%$ of the questions in the workbook are in the "Measurement and Geometry" domain, only 3.18\% are in the "Data" domain. On the other hand, in the TIMSS 2019 exam, the percentage of questions asked in the "Data" content domain has a higher rate of $20 \%$.

When the distribution of the questions in the workbook according to the cognitive levels was examined, it was determined that $51.27 \%$ of the questions were at the applying level. This finding is greater than the ratio of applying level questions (40\%) asked in the TIMSS 2019 exam. However, $34.39 \%$ of all questions in the workbook are at the knowing level, which is lower than the rate in TIMSS 2019 (40\%). Similarly, 14.13\% of all questions are included in the reasoning level. $20 \%$ of the questions in the TIMSS 2019 were at the reasoning level.

As a result of the research, it was found that the percentage of the questions belonging to the "Numbers" domain was similar to TIMSS 2019. However, while there are more questions in the "Measurement and Geometry" content domain compared to TIMSS, it has been determined that the percentage of questions belonging to the "Data" domain is relatively low compared to the TIMSS exam. The results of this study are similar to the results of Toptaş et al. (2012). The question rates of the workbooks on the "Numbers" content domain are similar to TIMSS. However, the researchers reported that the question rate for the "Measurement and Geometry" domain was lower than TIMSS, and the "Data" topic included a large number of questions from TIMSS (Toptaş et al., 2012). In this study, however, these content domains showed the opposite results. The fact that the percentage distributions of the questions in the workbook according to their content domains differ with TIMSS will affect the students' success in this exam.

According to their cognitive levels, the distribution of the questions in the workbook showed that the questions were mainly at the applying level. This is a positive result of the study. Because the cognitive level of applying is higher than the knowing level. However, compared to the 
percentages of questions in the TIMSS exam, the questions in the reasoning level are well below the percentage of TIMSS questions. This, on the contrary, is a negative result, showing that cognitively higherlevel questions were given less space in the book. In studies conducted in this field at the primary school level, it has been found that the questions in the course and workbooks are generally located at lower cognitive levels (Çilingir \& Artut, 2016; Üredi \& Hakan, 2020). Therefore, the fourth-grade workbook should include more questions on the cognitive level of "reasoning". In terms of content domains, more questions should be included in the "data" domain.

\section{Kaynakça / References}

Aydoğdu-İskenderoğlu, T. ve Baki, A. (2011). Classification of the questions in an 8th grade mathematics textbook with respect to the competency levels of PISA. Education and Science, 36(161), 287-301.

Ayvacı, H. Ş. ve Türkdoğan, A. (2010). Yeniden yapılandırılan Bloom taksonomisine göre fen ve teknoloji dersi yazılı sorularının incelenmesi. Türk Fen Eğitimi Dergisi, 7(1), 13-25.

Baker, D., Knipe, H., Cummings, E., Blair, C. and Gamson, D. (2010). One hundred years of elementary school mathematics in the United States: A content analysis and cognitive assessment of textbooks from 1900 to 2000. Journal for Research in Mathematics, 41(4), 383-423.

Beckmann, S. (2004). Solving algebra and other story problems with simple diagrams: A method demonstrated in grade 4-6 texts used in Singapore. The Mathematics Educator, 14(1), 42-46.

Bowen, A. G. (2009). Document analysis as a qualitative research method. Qualitative Research Journal, 9(2), 27-40.

Cai, J. (2008). Some highlights of the similarities and differences in intended, planned/implemented, and achieved curricula between China and the United States. In Z. Usiskin and E. Willmore, (Eds.). Mathematics curriculum in Pacific Rim countries-China, Japan, Korea, and Singapore. Information Age.

Cai, J. and Ni, Y. (2011). Investigating curricular effect on the teaching and learning of mathematics in a cultural context: Theoretical and methodological considerations. International Journal of Educational Research, 50(2), 65- 70. 
Corbin, J. and Strauss, A. (2008). Basics of qualitative research: Techniques and procedures for developing grounded theory (3th ed.). Thousand Oaks, CA: Sage.

Çalışkan, N., Kahya, E. ve Durmus, Y. T. (2018). An analysis of mathematics questions of the Tpese exam according to cognitive levels of TIMSS 2015. Journal of History Culture and Art Research, 7(5), 67-82.

Çilingir, E. ve Artut, P. D. (2016). 4. sınıf TIMMS 2011 matematik soruları ile matematik ders kitabındaki sorularin bilişsel alanlara göre incelenmesi. Electronic Turkish Studies, 11(21), 79-94.

Delil, H. (2006). An analysis of geometry problems in 6-8 grades Turkish mathematics textbooks. (Yüksek lisans tezi). Ortadoğu Tenik Üniversitesi Eğitim Bilimleri Enstitüsü, Ankara.

Delil, A. (2019). How fifth graders are assessed through central exams in Turkey: A comparison with TIMSS 2019 assessment framework. International Online Journal of Educational Sciences, 11(3), 222-234.

Fan, L., Zhu, Y. and Miao, Z. (2013). Textbooks research in mathematics education: Development, status and direction. ZDM, 45, 633-646.

Güner, N. (2015). 6.-8. sınıf matematik ders kitaplarındaki geometri, veri ve olasılık sorularının TIMSS bilişsel düzeylerine göre sınıflandırılması. Pamukkale Üniversitesi Ĕ̆itim Fakültesi Dergisi, 37(37), 77-90.

Milli Eğitim Bakanlığ1 [MEB]. (2018). Matematik dersi öğretim programı (ilkokul ve ortaokul 1, 2, 3, 4, 5, 6, 7 ve 8. sinfflar). Ankara: MEB.

Milli Eğitim Bakanlığı [MEB]. (2020). TIMSS 2019 Türkiye ön raporu. Ĕ̆itim Analiz ve Değerlendirme Raporları Serisi No: 15. Ankara: MEB.

Mullis, M. (2017). Introduction. In I. V.S. Mullis ve M. O. Martin (Ed.) TIMSS 2019 Assessment Frameworks. TIMSS \& PIRLS International Study Center, Lynch School of Education, Boston College and International Association for the Evaluation of Educational Achievement (IEA).

Mullis, I. V. S., Martin, M. O., Foy, P., Kelly, D. L. and Fishbein, B. (2020). TIMSS 2019 International Results in Mathematics and Science. Boston College, TIMSS \& PIRLS International Study Center.

Reys, B. J. and Reys, R.E. (2006). The development and publication of elementary mathematics textbooks: Let the Buyer Beware! Phi Delta Kappan, 87(5), 377-384.

Savaş, E., Olkay, E., Turan Ekmekçi, N. ve Savaş, S. (2020). İlkokul 4. sınıf matematik çalışma kitabı. H. Yaman (Ed.). MEB yayınları. 
Schmidt, W. H., McKnight, C. C., Houang, R. T., Wang, H., Wiley, D. E., Cogan L. S. and Wolfe, R. G. (2001). Why school matter. A crossnational comparison of curriculum and learning. Jossey-Bass.

Stein, M.K., Remillard, J. and Smith, M.S. (2007). How curriculum influences student learning. In F. K. Lester, Jr., (Ed.), Second handbook of research on mathematics teaching and learning (p.319-369). Information Age.

Şaban, İ. H. (2019). Matematik ders kitapları cebir öğrenme alanındaki soruların PISA matematik yeterlik düzeylerine göre incelenmesi. (Yüksek lisans tezi). Hacettepe Üniversitesi Eğitim Bilimleri Enstitüsü, Ankara.

Toptaş, V., Elkatmış, M. ve Karaca, T. (2012). İlköğretim 4. sınıf matematik programının öğrenme alanları ile matematik öğrenci çalışma kitabındaki soruların zihinsel alanlarının TIMSS'e göre incelenmesi. Ahi Evran Üniversitesi Kırşehir Ĕ̆itim Fakültesi Dergisi, 13(1), 17-29.

Üredi, L. ve Hakan, U. (2020). İlkokul matematik ders kitaplarında bulunan ünite değerlendirme sorularının yenilenmiş Bloom taksonomisine göre incelenmesi. Mersin Üniversitesi Ĕ̆itim Fakültesi Dergisi, 16(2), 432-447.

Valverde, G. A., Bianchi, L. J., Wolfe, R. G., Schmidt, W. H. and Houang, R. T. (2002). According to the book: Using TIMSS to investigate the translation of policy into practice through the world of textbooks. Springer Science \& Business Media.

Yıldırım, A. ve Şimsek, H. (2006). Sosyal bilimlerde nitel araştırma yöntemleri. Ankara: Seçkin Yayınları.

\section{Kaynakça Bilgisi / Citation Information}

Özçakır Sümen, Ö. (2021). Dördüncü sınıf matematik çalışma kitabında yer alan soruların TIMSS Sınavı bağlamında incelenmesi. OPUSUluslararası Toplum Araştırmaları Dergisi, 18(Eğitim Bilimleri Özel Sayıs1), 4107-4125. DOI: 10.26466/opus.927449. 